\title{
Single-mode solid-state polymer dye laser fabricated with standard I-line UV lithography
}

\section{Balslev, Søren; Mironov, Andrej; Nilsson, Daniel}

Published in:

Quantum Electronics and Laser Science Conference, 2005. QELS '05

Link to article, DOI:

10.1109/QELS.2005.1548962

Publication date:

2005

Document Version

Publisher's PDF, also known as Version of record

Link back to DTU Orbit

Citation (APA):

Balslev, S., Mironov, A., \& Nilsson, D. (2005). Single-mode solid-state polymer dye laser fabricated with standard I-line UV lithography. In Quantum Electronics and Laser Science Conference, 2005. QELS '05 (Vol. 2). IEEE. https://doi.org/10.1109/QELS.2005.1548962

\section{General rights}

Copyright and moral rights for the publications made accessible in the public portal are retained by the authors and/or other copyright owners and it is a condition of accessing publications that users recognise and abide by the legal requirements associated with these rights.

- Users may download and print one copy of any publication from the public portal for the purpose of private study or research.

- You may not further distribute the material or use it for any profit-making activity or commercial gain

- You may freely distribute the URL identifying the publication in the public portal 


\title{
Single-mode solid-state polymer dye laser fabricated with standard I-line UV lithography
}

\author{
S. Balslev, A. Mironov, D. Nilsson and A. Kristensen \\ MIC - Department of Micro and Nanotechnology, Technical University of Denmark (DTU) \\ Oersteds Plads, building 345 east, 2800 Kgs. Lyngby, Denmark \\ sba@mic.dtu.dk
}

\begin{abstract}
We present single-mode solid-state polymer dye lasers fabricated with standard UV lithography. The lasers use a high-order Bragg grating and rely on index-tuning of a photosensitive polymer for waveguiding. The gain medium is Rhodamine $6 \mathrm{G}$.

(C)2005 Optical Society of America

OCIS codes: (140.2050) Dye Lasers; (140.3410) Laser Resonators
\end{abstract}

\section{Introduction}

Integration of optical transducers is considered an important issue for future lab-on-a-chip microsystems, as light source integration in lab-on-a-chip systems eliminates the ever-present problem of optical alignment of external light sources to chips [1]. One approach is based on forming laser resonators via microlithography on laser dye doped polymer.

Lasers on lab-on-a-chip devices mainly find application in sensor systems and single mode lasers open the possibility of interference based sensing [2,3]. We have therefore focused on developing a single mode laser light source that can be patterned with a cheap parallel standard technique, avoiding the use of sub-micrometer structures. Here we present a laser fulfilling these requirements. It is formed entirely in polymer and based on a high order Bragg grating distributed feedback resonator. The gain medium is Rhodamine $6 \mathrm{G}$ embedded in the polymer matrix and it is pumped by a frequency doubled $\mathrm{Nd}$ :YAG laser.

The device presented here is very simple in fabrication, requiring three spin process polymer depositions and a single standard (I-line) UV lithographic step. The substrate can be any reasonably flat material that can withstand being heated to $90^{\circ} \mathrm{C}$. The substrate independence and the gentle fabrication process make our device feasible for integration with other components such as waveguides, microfluidic channels or other microfabricated structures, we have earlier demonstrated this principle with another type of on-chip laser [4].

\section{Laser structure}

The laser resonator consists of a number of bars of dye doped SU-8 covered with PMMA, this forms a slab waveguide wherein the light travels as a plane wave along the $x$-axis (see Fig. 1). The dye (Rhodamine 6G) doped SU-8 is $6 \mu \mathrm{m}$ thick and the PMMA layer is $4 \mu \mathrm{m}$ thick.

Due to the structure, the refractive index in the slab waveguide is modulated between 1.592 (SU-8 + dye) and 1.49 (PMMA). This modulation creates a Bragg grating with a period of $32.6 \mu \mathrm{m}$ consisting of $12.6 \mu \mathrm{m}$ of SU-8 and $20 \mu \mathrm{m}$ of PMMA. This long period conforms with conventional I-line UV lithography and lies well within normal resolution. At the lasing wavelength $(551 \mathrm{~nm})$, the Bragg reflection orders are spaced about $3 \mathrm{~nm}$ apart.

The bar in the middle of the array is a little wider (in the x-direction, see Fig. 1) than the rest, in order to introduce a $\pi / 2$ phase shift. This turns the Bragg grating into a DFB resonator with a single resonance for each Bragg reflection order.

In order to ensure that only a single transverse mode in the structure is lasing, the waveguiding regions with dye doped SU-8 support only a single transverse mode. The regions are made single mode by structuring them as asymmetric waveguides with a buffer that has a refractive index only 0.001 lower than the dye doped SU-8 core (Fig. $1 \mathrm{c}$ ). This small difference in refractive index is achieved by using the fact that the refractive index of SU-8 increases slightly when adding Rhodamine 6G [5].

When the light exits the dye doped SU-8 regions, it travels into the PMMA regions that are antiguiding since the SU-8 buffer has a higher refractive index than the PMMA. The light is confined upwards due to the low refractive index of air. The light is still guided in the PMMA regions, albeit with a loss. 
a)

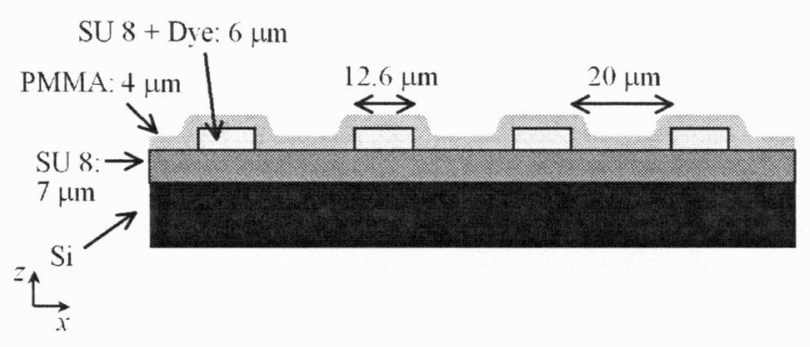

b)

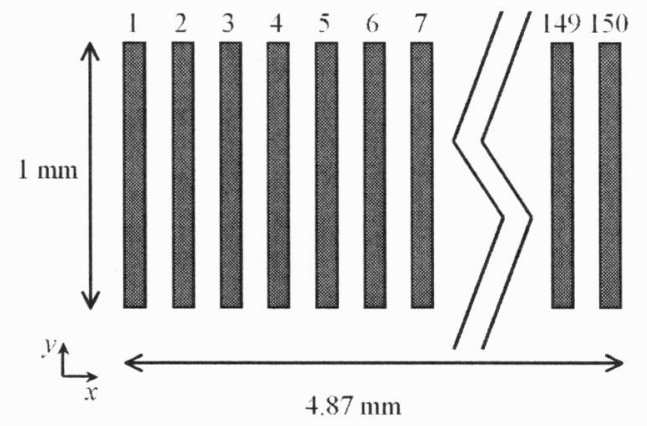

c)

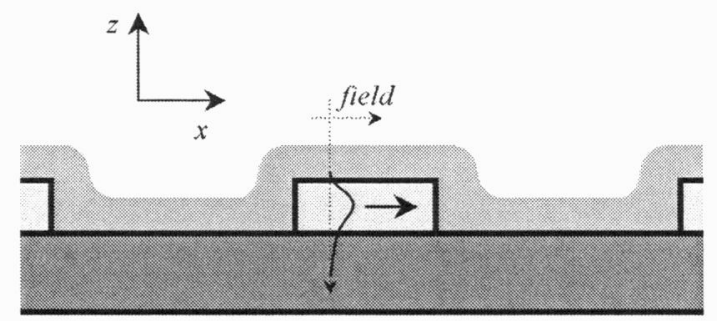

Fig. 1. a) Schematic of laser resonator design (side view). The dye doped SU-8 polymer bars and the interleaving PMMA compose a Bragg grating due to the differences in refractive index. b) Schematic of the laser structure seen from above (top view). The laser dye is pumped from above by a frequency doubled Nd:YAG laser and the dye laser light is emitted parallel to the substrate i.e. in the chip plane. c) The electromagnetic field travelling in part of the structure, only one transverse mode is allowed in the doped SU-8 regions. We have not determined the exact field shape in the PMMA region.

In fabrication, a pure $7 \mu \mathrm{m}$ SU-8 layer is deposited on a Silicon substrate, flood exposed and hard-baked. This layer forms the buffer of the waveguiding structures. The dye doped SU-8 is defined on top of the first SU-8 layer via a standard UV lithographic process for SU-8 photoresist. Finally the top layer of PMMA is spun on and the PMMA solvent evaporated.

\section{Characterization}

The emission from the dye laser was measured using a spectrometer with a $0.15 \mathrm{~nm}$ FWHM response. Fig. 2 shows a spectrum taken with a Nd:YAG pump pulse energy density of $396 \mu \mathrm{J} / \mathrm{mm}^{2}$. The laser line at $551.4 \mathrm{~nm}$ has a linewidth below the resolution limit of the spectrometer. The lasing threshold lies at about $210 \mu \mathrm{J} / \mathrm{mm}^{2}$ and the emitted light was purely horizontally polarised, i.e. in the chip plane.

a)

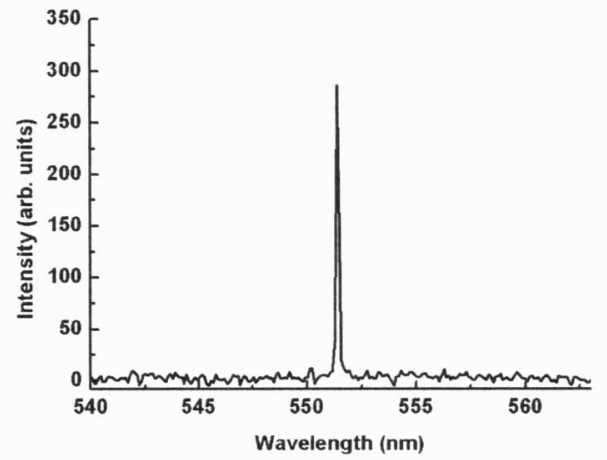

b)

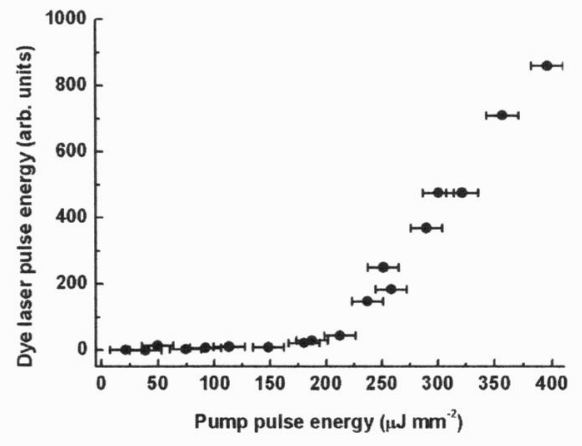

Fig. 2. a) Emission spectrum from the dye laser when pumped with $5 \mathrm{~ns}$ pulses at a pump energy density of $396 \mu \mathrm{J} / \mathrm{mm}^{2}$. The linewidth reflects the limited resolution of the spectrometer $(0.15 \mathrm{~nm})$. b) Dye laser output as function of pump energy, the lasing threshold is observed at $210 \mu \mathrm{J} / \mathrm{mm}^{2}$. The horizontal error bars on the pump energy is due to pump laser fluctuations. The error on the vertical axis is smaller than the size of the dots. 


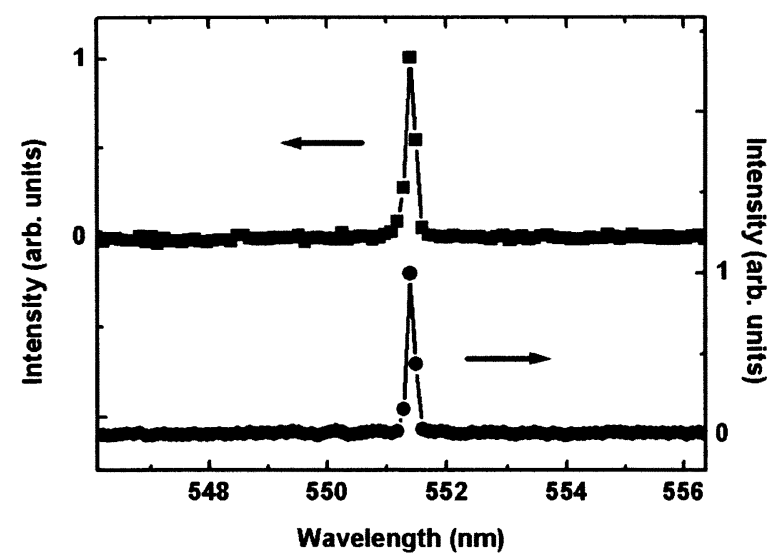

Fig. 3. Spectra from two lasers of the same type, demonstrating a high chip-to-chip uniformity of the laser emission. The points indicate the individual spectrometer CCD readings and the observed linewidth is caused by the spectrometer FWHM response.

A high degree of lasing wavelength uniformity for different chips of the same type can be observed. Fig. 3 shows a zoom of the spectrometer readings of the laser lines from two chips. Due to the way the light is coupled out of the lasers it has not been possible to measure the efficiency, however other microchip lasers based on dye dissolved in a fluid has efficiencies around $1 \%$ [6].

\section{Conclusion}

In conclusion we have demonstrated a new type of solid-state polymer dye laser fabricated with standard UV lithography. The lasers display single-mode operation from a high order Bragg grating distributed feedback resonator. Due to the fabrication method, the laser is easily integrated with waveguides, microfluidics and other components for lab-on-a-chip purposes, and the devices have a high chip-to-chip uniformity.

\section{References}

[1] E. Verpoorte, "Chip vision-optics for microchips", Lab Chip, 3, 42N-52N, 2003

[2] A. Brecht and G. Gauglitz, "Optical probes and transducers," Biosensors and Bioelectronics 10, pp. 923-936 (1995)

[3] L. lading, L.B. Nielsen and T. Sevel, "Comparing Biosensors," Proceedings of the IEEE Sensors 2002, 229-232 (2002)

[4] S. Balslev, B. Bilenberg, O. Geschke, A.M. Jorgensen, A. Kristensen, J.P. Kutter, K.B. Mogensen and D. Snakenborg, "Fully integrated optical system for lab-on-a-chip applications," in Proceedings of the $17^{\text {th }}$ IEEE Conference on Micro Electro Mechanical Systems, MEMS 2004 , (Institute of Electrical and Electronics Engineers, Maastricht, 2004), pp. 89-92

[5] D. Nilsson, S. Balslev and A. Kristensen, "Solid Polymer Dye Laser Based on a Single Mode SU-8 Planar Waveguide", Proceedings of MicroTAS 2004, the eighth international Conference on Miniaturised Systems for Chemistry and Life Sciences, Malmö, Sweden, 26-30 September 2004, T. Laurell, J. Nilsson, K. Jensen, D.J. Harrison and J.P. Kutter eds., Royal Society of Chemistry, Cambridge, United Kingdom (2004), Vol. 2, pp. 369-371

[6] S. Balslev and A. Kristensen, "High order Bragg grating microfluidic dye laser", The 2004 CLEO/IQEC conference, San Francisco, California, USA, May 16-21, 2004 CLEO/IQEC and PhAST Technical Digest on CD-ROM (The Optical Society of America, Washington, DC, 2004), presentation number CFM7 